\title{
TRAVESSIAS NA EJA: A EXTENSÃO UNIVERSITÁRIA COMO PONTE DO FAZER, DO APRENDER, DO PENSAR
}

\author{
Maria Rosa Rodrigues Martins de Camargo* \\ José Carlos Miguel ${ }^{* *}$ \\ Eliana Marques Zanata ***
}

\begin{abstract}
RESUMO: Para articular reflexôes acerca da produção de conhecimento, no campo da Educação de Jovens e Adultos (EJA), na dinâmica da extensão universitária, focamos o Programa de Educação de Jovens e Adultos (Peja), desenvolvido na Universidade Estadual Paulista "Júlio de Mesquita Filho" (Unesp) desde 2001. Os objetivos que organizam a atuação no Programa sáo: o acompanhamento de pessoas pouco ou nada escolarizadas e a formação de educadores, graduandos em licenciaturas diversas que atuam nas atividades de ensino, em instituiçóes sociais diversas. $\mathrm{O}$ artigo remete a uma análise sistemática das fontes materiais utilizadas nas propostas de intervenção e estudos, aportada na história cultural com foco nas práticas culturais, em estudos da linguagem na perspectiva da interlocução e na abordagem histórico-cultural, base para a construção de objetos de pensamento. A imersão nas fontes traz à superfície temas que contribuem para a reflexão ao constituíremse em subsídios inerentes às práticas educacionais, culturais, políticas.
\end{abstract}

Palavras-chave: Educação de jovens e adultos. Extensão universitária. Saberes compartilhados. Saberes produzidos.

\footnotetext{
* Universidade Estadual Paulista “Júlio de Mesquita Filho”, Instituto de Biociências, Rio Claro, SP., Brasil. E-mail de contato: mrosamc@rc.unesp.br.

** Universidade Estadual Paulista "Júlio de Mesquita Filho", Faculdade de Filosofia e Ciências, Marília, SP., Brasil. E-mail de contato: jocarmi@terra.com.br.

*** Universidade Estadual Paulista "Júlio de Mesquita Filho", Faculdade de Ciências, Bauru, SP., Brasil. E-mail de contato: lizanatafc@gmail.com.
} 


\title{
Crossing bridges at youth and adult education: sharing knowledge through university extension courses
}

\begin{abstract}
To articulate reflections on the production of knowledge in the field of Youth and Adult Education, EJA, in the dynamics of University extension courses, we focus on the Youth and Adult Education Program (Peja), developed at Universidade Estadual Paulista "Júlio de Mesquista Filho" (Unesp) since 2001. The objectives that organize the activities in the program are: assisting people with little or no instruction, and training educators and graduate students pursuing various Bachelor's degrees who work in teaching activities in various social institutions. The article refers to a systematic analysis of the material sources used in the intervention proposals and studies, based upon the cultural history with a focus on cultural practices, in language studies under the perspective of dialogue and the cultural-historical approach, the basis for the construction of objects of thought. Immersion in the sources brings to the surface issues that contribute to the reflection when constituting inherent subsidies to educational, cultural and political practices.
\end{abstract}

Keywords: Youth and adult education. University extension courses. Shared knowledge. Knowledge production.

\section{INTRODUÇÃO}

$\mathrm{P}$

ara compreender a Educação de Jovens e Adultos como campo de pesquisa é condição sine qua non considerar as tensões do campo que perpassam, entre outros aspectos, a relação entre escolarização e não-escolarização, tensão essa que traz à visibilidade temas outros a serem considerados. À especificidade do campo - EJA - alia-se o entrelaçamento de temas que vão emergindo múltiplos porque carregam vivências, saberes e dizeres dos atores envolvidos: graduandos educadores em formação e pessoas pouco escolarizadas.

É nossa preocupação o fato de que o movimento pela educação de jovens e adultos ainda é influenciado por paradigmas situados no con- 
texto de suprimento, suplência e educação compensatória em que pese avanços ocorridos nas duas últimas décadas, seja no aperfeiçoamento da legislação e políticas efetivas, em especial, discutindo diretrizes curriculares para a EJA (BRASIL, 2002), seja no movimento para constituição de um campo teórico que busca considerar a sua especificidade pondo em pauta a necessidade de profissionalização docente e a superação da ambivalência do lugar que ocupa quem sabe ler e escrever e quem não sabe, seja na ampliação de vertentes que põem em discussão abordagens e olhares que focam os sujeitos aprendizes na singularidade de suas manifestaçôes. Algumas discussões encontram-se em Marques; Zanata (2010), Carvalho (2012), Pedralli; Cerutti-Rizzatti (2013), Camargo (2014), Miguel (2014).

Neste artigo há a proposta de articular algumas reflexóes acerca da produção de conhecimento sobre Educação de Jovens e Adultos (EJA) na dinâmica da extensão universitária, tomando como exemplo o Programa de Educação de Jovens e Adultos (Peja/Unesp) sua produção ao longo dos anos de existência, os objetivos propostos, as realizaçóes cotidianas. Adentrando-nos em uma análise sistemática consideramos como fontes materiais as práticas a que se recorre para produzir as propostas de intervenção (em constante movimento de reflexão), as açôes empreendidas para o trabalho didático pedagógico (em constante reelaboração com os sujeitos envolvidos), e as formas diversas de registros produzidos (cadernos de campo, registros orais, escritos pelas/os próprias/os educandas/ os), aportando-nos em autores na história cultural (CERTEAU, 1996), em estudos da linguagem na perspectiva dialógica e de interlocução (FREIRE, 1997; BAKHTIN, 1986), na abordagem histórico-cultural. (VIGOTSKI, 2001) Destacamos que as fontes produzem-se tendo como eixo organizador saberes compartilhados e os resultados motivados, particularmente, apoiando-se na fala dos sujeitos participantes, para, então, argumentar a favor do tipo de contribuição que a extensão universitária pode trazer ao campo da EJA. O propósito é impulsionar o debate e a reflexão, na extensão universitária, entre pesquisadores de EJA com atuação efetiva na educação de jovens e adultos.

Da extensão universitária, argumentamos de acordo com o Plano Nacional de Extensão Universitária (PNExt) de 2011-2020 (RENEX, 2012) ao apontar que "[...] a Universidade deve considerar os 
conhecimentos gerados com as necessidades reais da sociedade fazendo mudanças e adaptaçóes ao ensino e à pesquisa, para oferecer soluções a problemas eminentes [...]". (ARAÚJO et al, 2012) Ao cumprimento do propósito de sua existência, como lócus de discussão e criação de novas metodologias e tecnologias com vistas à solução de situaçôes-problemas apresentados por segmentos da sociedade, adere-se à articulação que envolve ensino e pesquisa. Nessa dimensão evidencia-se a atuação e a produção no Peja/Unesp articulando, no espaço institucional da extensão universitária, matéria para reflexão de uma educação que se pauta no fazer, aprender e pensar, como impulsionadoras de metodologias e tecnologias outras, que daí podem advir.

\section{GESTANDO UM PROGRAMA DE EDUCAÇÃO DE JOVENS E ADULTOS: TRAVESSIAS DE FORMAÇÃO NA EXTENSÃO UNIVERSITÁRIA}

No final do ano de 2000 a Pró-Reitoria de Extensão Universitária e Assuntos Comunitários (Proex) da Universidade Estadual Paulista "Júlio de Mesquita Filho" (Unesp) instituiu um programa voltado para a complementação da escolarização básica de servidores da universidade, convocando docentes vinculados a cursos de graduaçáo em Pedagogia ou Letras dos diversos campi que tivessem alguma experiência na educação de jovens e adultos ou que, ao menos, tivessem sensibilidade para o problema.

Feito um diagnóstico inicial constatou-se demanda variada em todos os campi, havendo casos nos quais o número de servidores inscritos era bastante reduzido. Decidiu-se, então, ampliar as açóes de forma a congregar esforços desenvolvidos isoladamente no contexto da Unesp, o que possibilitou ampliá-las com novas salas de aulas e inserção de bolsistas, voluntários e estagiários.

Assim, criou-se uma ação específica voltada para atendimento dos servidores e outra voltada ao atendimento de demandas da comunidade externa, tendo sido instaladas salas de aula na periferia das cidades, sedes da Unesp, em parceria com escolas, entidades de classe, associaçóes de moradores e igrejas. 
Dito isso, cabe ressaltar que o Programa de Educação de Jovens e Adultos (Peja/Unesp) vai se constituindo pelos projetos de extensão universitária, atualmente desenvolvidos em sete unidades da Unesp ${ }^{1}$ que, em sua diversidade, corrobora uma das açóes da universidade voltada à articulação entre teoria e prática nessa área do conhecimento e à integração da universidade à comunidade. Está em pauta contribuir para minimizar o analfabetismo, produzir material didático e bibliográfico e pôr em discussão políticas públicas nesse âmbito, tendo como norte os fundamentos da educação de jovens e adultos no contexto de prerrogativas que se tornam hegemônicas a partir do processo de redemocratização da sociedade brasileira. A rigor, compreende-se que nas Ciências Humanas a pesquisa tem campo fértil na extensão universitária.

Em nossa compreensão, o encaminhamento de questóes concernentes à EJA, do analfabetismo e/ou (não)escolarização à formação de educadores, da busca de posturas didático-pedagógicas à busca de focos de análise que ampliem interpretaçóes dessas questôes, exige engajamento da sociedade civil organizada, ação mais efetiva do Estado, e atuação compromissada da instituição acadêmica (nosso contexto de atuação), visando garantir o direito à educação ao longo da vida. Por isso busca-se, na parceria com escolas, associaçóes de moradores, igrejas, organizaçóes não-governamentais a constituiçáo de ambientes de aprendizagem e formação que possibilitem a inserção do educando jovem ou adulto. Isso exige dos educadores em formação, bolsistas graduandos, sensibilidade e disponibilidade para refletir sobre a sua trajetória de formação e busca para aprender e construir, coletivamente, no fazer do trabalho educativo, novos parâmetros para o exercício docente.

$\mathrm{Na}$ trajetória histórica da constituição do Peja/Unesp, e em especial neste artigo, destacamos um eixo de análise que emerge em nossos registros $^{2}$ : trata-se de um fazer e aprender marcado pela singularidade das manifestaçôes dos participantes. Com as dificuldades inerentes ao trabalho em EJA, raramente se constata algum depoimento de bolsista de que não valha participar do projeto. $\mathrm{MIL}^{3}$ graduanda do curso de Pedagogia, atuou por dois anos como bolsista e assim se manifestou em reunião de avaliação do trabalho: 
É um trabalho muito legal. Apesar de ter que me deslocar três vezes por semana para um Posto de Saúde localizado muito longe da Unesp é algo que me motiva muito. Inicialmente, tentei ser professora como a maioria é, fazendo valer a autoridade de ser professora. A coisa enrolou. Tive que mudar. Passei a explorar a história de vida deles, de onde vieram, quem eles eram, por que foram para a escola, enfim, considerei a identidade cultural deles, a afetividade no relacionamento... Estou muito feliz com os resultados que começam a aparecer e pretendo atuar na EJA depois de formada. [Acervo do Peja/Unesp, 2014]

O depoimento de MIL traz à tona o problema da especificidade da atuação docente na EJA e não só. Sensibiliza-nos a considerar que a EJA começa a se constituir como um corpo teórico que, embora de forma lenta, progressivamente incorpora reflexóes e conquistas recentes da pesquisa em Educação, avança no reconhecimento como direito público subjetivo e, na prática, estabelece que é dever do Estado a oferta desse serviço público. (ARROYO, 2001) Náo se pode, ainda, descuidar do fato de que toda a sociedade civil organizada tem um papel a desempenhar para o reconhecimento de um direito fundamental historicamente negado. De fato, a partir dos anos oitenta do século passado, registra-se

[...] um movimento de queda do analfabetismo absolutamente lento e gradual, o que sugere tratar-se de fenômeno que tem curso próprio, imune, no caso brasileiro, à interferência de determinaçóes legais, de planos, de campanhas e principalmente de discursos contra o analfabetismo. (FERRARO, 2004, p. 195)

Ferraro nos lembra que, perversamente, a tendência de queda do analfabetismo não resulta, ainda, da efetividade das políticas públicas e que o analfabetismo representa apenas uma forma extrema de exclusão, dentre as múltiplas formas de apartheid social que se mostram atreladas, e que náo podemos tratar como se isoladas fossem. Quando a universidade se propóe a essa discussão, insere-se no contexto de um conjunto de esforços em prol da integração entre a instituição e a comunidade 
à qual está vinculada, buscando desempenhar o seu papel histórico de produção de conhecimento e de formulação de natureza teórico-prática. Parece-nos que se trata de destacar a importância da aprendizagem de jovens e adultos, assumindo compromissos com uma perspectiva de educação ao longo da vida, de forma a facilitar a participação de todos na construção do desenvolvimento sustentável e solidário e de busca de uma cultura com base na liberdade, equidade, justiça e respeito pelas diferenças. Sobretudo trata-se, a nosso ver, de construir uma relação sinérgica entre educação formal e educação não-formal, na qual a formaçấo de educadores é um dos pilares. Nessa perspectiva, assumimos com Paulo Freire que

[...] ensinar não é transferir conhecimentos, conteúdos; nem formar é açấo pela qual um sujeito criador dá forma, estilo ou alma a um corpo indeciso e acomodado. Não há docência sem discência, as duas se explicam e seus sujeitos, apesar das diferenças que os conotam, não se reduzem à condição de objeto um do outro. Quem ensina aprende ao ensinar e quem aprende ensina ao aprender. Quem ensina, ensina alguma coisa a alguém. (FREIRE, 1997, p. 25)

Pela inserção na prática docente, nos projetos Peja/Unesp, vislumbra-se considerar o fazer pedagógico em outra dimensão aportando-o na tensão com as referências de cultura escolar já construídas. Para os educadores em formação, o aspecto fundamental do processo se coloca justamente nas experiências de trabalho de natureza teórico-prática propiciadas pela inserção nos projetos.

O processo de formação de educadores para a EJA, pela via de um projeto de extensão universitária, constitui-se como um espaço no qual uma ação de cunho social se torna objeto de interesse para a pesquisa e para o ensino. E pela sistematização das ações desenvolvidas em relatórios, na redação de artigos e apresentação de trabalhos em eventos científicos, possibilitam-se rumos à emancipação intelectual dos estudantes envolvidos, e docentes em formação continuada ${ }^{4}$, não apenas pelo profícuo exercício de elaboração de artigos e representações, como pela possibilidade de reflexáo sobre o trabalho efetivamente desenvolvido. 
OBS atuou por 3 anos como bolsista do projeto. Agora, prestes a concluir o Mestrado em Educação, no qual aborda a perspectiva metodológica de resolução de problemas na EJA, considera que:

No começo ficava muito preocupada; achava que não ia dar conta. Parecia que os alunos não entendiam. Eu queria desenvolver uma ação pedagógica que se pautava pela problematização, mas eles queriam cópias na alfabetização e continhas em Matemática. Jogo eles consideravam coisa de criança. Era a visäo que eles tinham de educação. Deu muito trabalho, mas hoje eles são muito ativos e críticos. Sinto que cresceram como seres humanos e eu estou me fazendo uma educadora de fato, apesar de todas as dificuldades. Não consigo me ver atuando em outra área da educação. [Acervo do Peja/ Unesp, 2014]

O depoimento de OBS aponta para a importância da transposição didática e para o estabelecimento de uma relação dialógica na sala de aula de EJA. (FREIRE, 1997) Mais ainda, indica que o trabalho na EJA exige perseverança, generosidade e desenvolvimento da capacidade de acreditar no outro. Trata-se de pôr em prática um processo de produção de sentidos de aprendizagem e de negociação de significados.

Sem dúvida, o desenvolvimento social exige dos agentes educacionais capacidade para descobrir e potencializar conhecimentos e aprendizagens de natureza global e permanente, elementos essenciais para a transformação educacional imposta pelas transformações globais. Mais do que perseguir os objetivos de escolarização formal de jovens e adultos, investindo na formação de educadores e buscando apontar subsídios para o encaminhamento de políticas públicas para essa área do conhecimento, uma proposta de educação de jovens e adultos no contexto da universidade deve se voltar para o estabelecimento de vínculos de natureza diversa com a população que lhe subsidia.

As palavras ditas e registradas acima, por educadoras/es em formação, são quase uma constante nas reunióes semanais dos projetos Peja/Unesp, chegando a fazer paralelos de relevância entre o curso de graduação e a atuação no projeto. $\mathrm{O}$ potencial formativo que articula 
teoria-prática-encontro com o inusitado em que se busca soluções para determinadas situaçóes de vida, inusitadas, trazidas por cada um/a entre educandos/as, a nosso ver, está nesse entrelaçamento teoria-prática-questóes da vida cotidiana, em que graduandos, educadoras/es em formação, se deparam com condiçóes inesperadas que os impulsionam a um constante repensar nas proposiçóes das atividades pedagógicas que organizam. A esse repensar acoplam-se noções de produção de conhecimento (inerente ao outro e a si mesmo), como se constituem as relaçóes em um processo pedagógico e seus limites, sobretudo possibilidades, das escolhas metodológicas (o como fazer). Nesse repensar, emergem condiçôes, inerentes a um praticar, e saberes compartilhados e mediados pela interlocução fértil entre sujeitos que se querem históricos, singulares.

Nessas travessias, inconclusas, aporta-se um dos objetivos do Peja/Unesp e sistematiza-se uma das fontes das reflexóes aqui trazidas, constituídas pelas práticas cotidianas nos encontros formais entre ensinantes e aprendizes. Quem é quem nesse processo?

\section{OS SUJEITOS DA EJA: IDENTIDADE CULTURAL, SUBJETIVIDADE, TRAVESSIA}

Uma rápida incursão na História da Educação Brasileira indica como características bem definidas o encaminhamento das elites dirigentes para processos de formação geral, isto é, de ensino propedêutico, sendo que às classes populares reserva-se um saber de natureza instrumental travestido, por vezes, de ensino profissionalizante. Também é necessário constatar que a negação do direito à educação formal sustenta-se a partir da negação de direitos fundamentais da pessoa humana tais como o direito à sobrevivência digna, à moradia em boas condiçôes, à saúde e à segurança, dentre outros.

Para não perder de vista a questão do direito, que também está nas escolhas, lemos MAR, que voltou a estudar já beirando os 40 anos de idade; primeiro veio para o Peja/Unesp, tomou coragem e, quando escreveu o trecho a seguir, estava prestes a concluir a quinta série. 
Para que então foram inventados os direitos humanos, se eles nãos são cumpridos e respeitados pela própria lei? Se muitas vezes os poderosos têm partilhado de muitas ilegalidades: a escravidão, a guerra, a época da ditadura que se era proibido o direito de se expressar e opinar sobre vários assuntos e a livre escolha de ser quem você é, de ser você verdadeiramente, de ter seus próprios gostos e crer naquilo que achar melhor para si mesmo, era proibido. Poder ser você mesmo é um dos maiores privilégios de sermos humanos. [Acervo do Peja/Unesp, 2011]

Eis o primeiro desafio para os educadores da EJA: onde é o lugar histórico de um processo de EJA que se coloca como transformador? Para nós, pensar a pertinência da EJA, no atual estágio da democracia brasileira, impóe pensá-la intransigentemente como direito público subjetivo tal como se coloca na legislação em vigor. A lógica é de que o Estado, que administra o excedente econômico, deve ser o responsável por esse serviço sob pena de inviabilizar o desenvolvimento econômico que pretendemos seja sustentável e solidário e de não contribuir para promover a justiça social.

JOS, educando do Peja, 29 anos, de lucidez admirável, fala muito bem e é articulado em seus propósitos. É carpinteiro de ofício, sabe bem porque resolveu estudar:

Quero aprender a ler e a escrever melhor porque preciso fazer o orçamento do serviço que contrato. É muito ruim depender dos outros para fazer isso. Apesar de me virar bem, porque faço tudo de cabeça, isso vai melhorar muito o meu trabalho. Agora, preciso fazer orçamento na internet, mandar o orçamento por e-mail para o freguês... Já melhorei bastante, mas posso avançar mais ainda... [Acervo do Peja/Unesp, 2013]

A Lei de Diretrizes e Bases da Educação Nacional - LDBEN 9394/96 - define diretrizes que afetam diretamente o trabalho em EJA. Ela aponta para outros encaminhamentos, incorporando uma concepção de formação ampliada que deve se sustentar na pluralidade das experiên- 
cias humanas. É no contexto de flexibilização - deslocamentos - que se colocam as alternativas de intermediação didático-pedagógica dos saberes, conhecimentos e da cultura popular na organização dos programas de ensino. Com base nessa ideia, os projetos Peja/Unesp atuam na busca de uma formação que visa avançar de um projeto de educaçáo/escola que adapta o aluno, para uma escola/educaçáo que emancipa o aluno.

Faz-se premente considerar a especificidade da EJA, o que implica na profissionalização docente neste campo do conhecimento; além disso, traz consequências para a formação ao se pensar um professor epistemologicamente curioso e que se proponha a pensar o problema da transposição didática, isto é, que atente para a noção conceitual de que para ser ensinada a ciência deve ser transformada, o que ocorre ao buscar entendê-la na dinâmica que lhe é inerente, e não na rigidez de resultados dados. O ponto de partida do trabalho pedagógico na EJA deve ser os saberes das vivências das/os educandas/os e o ponto de chegada, o conhecimento, por eles sistematizado. A travessia é o desafio do fazer com, do aprender na troca, do pensar compartilhado, educadoras/es e educandas/ os. MAR, educanda, confirma:

No PEJA não existe somente educadores e alunos, mas existe troca, alunos viram educadores e educadores viram alunos, e assim cada um troca experiências e aprendemos sempre com o outro. [Acervo do Peja/Unesp, 2012]

Desconsiderando-se esta prerrogativa, há o risco de se oferecer aos educandos, um ensino hermético, formalístico e distante dos modos de pensar e agir de sujeitos que, apesar de não-escolarizados, são detentores de saberes. É o problema da relação entre cultura primeira e cultura erudita, na perspectiva de Snyders (1994). Da problematização dessa relação, emergem as pessoas comuns, de carne e osso, nomeadas no dizer de Certeau (1996).

ELI, 59 anos, considerava-se, ao ingressar no Programa, "uma burra veia [sic]". Três anos depois, as palavras são outras, sua autoestima é outra: 
No começo, tremia de nervoso, minha mão suava. Mas a professora é muito boa. Devo muito a ela. Já não dependo de ninguém para anotar número de telefone. Para fazer compra, então, ninguém me engana. Sei muito bem quando está caro porque leio tudo o que me cai nas mãos. Mas, olha, preciso dizer que gosto muito de estar aqui porque vejo as pessoas, amigos que tem a mesma ansiedade e a mesma esperança que eu. [Acervo do Peja/ Unesp, 2013]

ELI evidencia a importância da construção de um ambiente positivo para a aprendizagem, no qual a principal característica pode ser o acolhimento. Ela é representante de um grupo social majoritário nos projetos Peja/Unesp, as mulheres, com idade acima de 50 anos. Para além da explicação do fenômeno pelo processo de emancipação da mulher, o aspecto da socialização, de pertinência social, parece-nos fator preponderante para o ingresso ou retorno à escola. Some-se a isso a referência que poucas fazem ao trabalho como determinante para a decisão posto que, ou são de prendas domésticas, ou já se aposentaram.

E o tempo também parece ser outro, como para DIR, que se "descobriu escritora” nas aulas do Peja/Unesp:

O tempo passa.

Para mim já se passaram cinquenta e quatro anos.

Nasci, cresci, vivi, aprendi, mas ainda encontrei tempo para aprender o que ainda náo aprendi.

Já pensou que maravilhoso seria o tempo para as pessoas que dizem que não têm tempo?

O tempo para mim está sendo o agora, e estou feliz por ter essa oportunidade nesse tempo de duas horas de aprendizado, que jamais pensei em tê-lo. Está muito bem aproveitado esse tempo. [Acervo do Peja/Unesp, 2010]

Ao entrar para o Peja/Unesp, em 2008, DIR retomou o pouco que sabia do exercício de escrever e deu continuidade colecionando textos, de início escrita tímida, depois cadernos de registro das aulas, caderno de poesia, e em 2014 'finalizou' uma história escrita para crianças 
que quer publicar em livro e com ilustrações feitas por crianças; finalizou, entre aspas pois, no dizer dela, sempre há alguma coisa a rever. Da interlocução com educadoras/es leitoras/es, no espaço físico e relacional dos encontros, à interlocução consigo mesma na revisão de um texto, desvela-se a potencialidade de um fazer próprio (CERTEAU, 1996), desvela-se a potencialidade de imersão na linguagem escrita que, para além de registro de suas vivências, torna-se motivo da vida. (BAKHTIN, 1986)

É nesse contexto identitário que se alocam os projetos de extensão universitária que compóem o Peja/Unesp. Acreditamos que uma proposta de educação de jovens e adultos impóe buscar o distanciamento da lógica do mercado e a superação de limitaçóes postas no contexto da LDBEN 5692/71, que conduziu as propostas de ensino de jovens e adultos ao desenvolvimento de um saber meramente instrumental, no contexto de alfabetizar para atender demandas ligadas ao âmbito de avaliaçóes externas. Trata-se de inserirmo-nos num movimento de continuidade de intermediação e consideração dos saberes, dito populares, e de ruptura com as crendices e formulações não científicas.

O Peja/Unesp, ao configurar-se na interpenetração da ação didático-pedagógica pautada na problematização da prática docente em EJA e consequente orientação técnico-pedagógica, do fazer investigativo à medida que se faz necessário analisar a prática para transformá-la, e da formulaçáo de procedimentos pedagógicos à luz de uma teoria, revela-se como importante contribuição educacional, social e política em aspectos como: o impulso à escolarização formal de jovens e adultos; o investimento nos processos de formação, inicial e contínua, de educadores para esse campo do conhecimento; a abertura a outras interpretaçôes de culturas identitárias que caminham lado a lado tocando-se mutuamente umas e outras; a condição de fazer emergir modos de ser, que se delineiam como manifestação de subjetividades que são imanentes a cada sujeito participante do processo. Coaduna-se com essa ideia o trecho escrito por MAP quando foi convidada, pela educadora, a registrar a aula do dia, no caderno de registros coletivos:

Hoje foi falado sobre o modo de falar. Por exemplo, na letra da música Asa Branca está escrito óios em vez de 
olhos. $A C$ [bolsista educadora] também disse que ouvir ou escutar são a mesma coisa. Eu hoje acordei as cinco horas da manhã, arrumei a marmita, depois lavei roupas e fiz almoço e depois limpei minha casa e depois vim para a escola. A MJ [outra educanda] disse que lá no norte se diz tomar uma pinga é tomar um 'mé. Toda vez que terminar um assunto e for começar outro temos que deixar parágrafo para que o texto fique correto. [Acervo do Peja/Unesp, 2004]

Com relação ao objetivo dos projetos em pauta, cuja proposição se organiza pelo deslocamento em direção a essas pessoas pouco escolarizadas, que carregam saberes e constituem histórias que se entrelaçam com trajetórias escolares, de trabalho e de vida, póe-se em foco a busca por práticas culturais que marcam seu dia a dia, em particular, as práticas que se efetivam pela e na leitura, escrita e cálculos. Esse deslocamento tem possibilitado o encontro com pessoas pouco escolarizadas, destacando-se mulheres, com idade entre 30 e 60 - também algumas acima de 70 - que se revelam afinadas com as leituras de mundo a sua volta e mais longe, com as soluçóes que buscam e dão às necessidades e demandas de sua vida cotidiana, e que se embrenham por veredas como descobrir-se escritora. Tais revelaçóes têm sido fonte e objeto de algumas produçóes acadêmicas que vêm sendo articuladas em projetos que desvelam histórias e fazeres singulares. Ressalve-se que a eleição de tal fonte possibilita a travessia de pessoas, da vala comum de índices não muito animadores, como por exemplo de analfabetismo, para um lugar, que lhes é de direito, em que se assentam como sujeitos históricos.

Da Educação de Jovens e Adultos. Das formulações aqui apresentadas, é preciso considerar que a atuação na extensão universitária, nos projetos aqui abordados, se dá numa zona de tensão permanente entre o geral (visóes de sociedade) e o particular (visóes da educação de jovens e adultos), a coletividade (propostas pedagógicas de cunho genérico) e o subjetivo (propostas que considerem saberes constituídos), o local (cada projeto em sua peculiaridade) e o ampliado (o que se vislumbra como utopia) porque o diagnóstico efetuado anualmente para desenvolvimento dos projetos do Peja/Unesp registra depoimentos dos educandos indicando a importância da ação praticada: ora para cobrir 
exigências do mercado do trabalho, ora pelo próprio desejo de avanço intelectual e melhor convívio social numa sociedade letrada, ora pelo prazer de estudar visto que não tiveram a oportunidade de fazê-lo na infância ou adolescência, ora pelo apego religioso (vários dizem se inscrever no projeto porque querem ler a Bíblia) etc.

Ao efetuar-se esse diagnóstico tem-se em vista uma melhor compreensão dos fatores condicionantes do acesso e permanência do educando jovem ou adulto no processo de escolarização formal, bem como a reelaboração constante dos programas de ensino e da metodologia de trabalho pedagógico nos espaços de atuação e uma busca de entendimento de questóes mais gerais da EJA, que se destacam na percepção de pessoas que nela se inserem. Essas formulaçóes encaminham algumas diretrizes para as açóes docentes no contexto da teoria histórico-cultural (VYGOTSKY, 2001), procurando compreender a forma como o educando adulto constrói o seu saber sobre o que é a leitura e a escrita, além de conteúdos culturais e científicos, e sua repercussão na vida cotidiana e subjetiva.

Ao focarmos as Diretrizes Curriculares Nacionais para a Educação de Jovens e Adultos (Resolução CNE/CEB no 1/2000), atentamos que elas reconhecem a EJA como modalidade da Educação Básica e como direito do cidadáo, o que se distancia da ideia de suprimento e compensação. Ao assumir as perspectivas de reparação de direito, equidade e qualificação, as diretrizes representam um avanço, defendendo a necessidade de considerar o perfil dos educandos e sua faixa etária com vistas à proposição de um modelo pedagógico que possa assegurar:

[...] equidade: distribuição específica dos componentes curriculares, a fim de propiciar um patamar igualitário de formação e restabelecer a igualdade de direitos e de oportunidades em face do direito à educação; diferença: identificação e reconhecimento da alteridade própria e inseparável dos jovens e dos adultos em seu processo formativo, da valorização do mérito de cada um e do desenvolvimento de seus conhecimentos e valores. (BRASIL, 2002, p. 17-18) 
É no contexto de responsabilização do Estado pela oferta de EJA e da formação de um professor educador sintonizado com as aspiraçóes singulares que se coloca a radicalidade de uma proposta de educação de jovens e adultos, as contribuições para a formaçáo docente e discente, para a reorganização curricular que se estabelecem no bojo de movimentos sociais e populares e de ações acadêmicas com vistas à articulação entre teoria e prática desenvolvidas em âmbito nacional.

Com base na tese de que aprendemos resolvendo situaçōes-problemas e formulando questóes, trata-se de encaminhar o trabalho pedagógico de modo a possibilitar amplo processo de interaçáo entre os sujeitos, na busca colaborativa de compreensão desses problemas que são levantados no contexto cultural e discutir a sequência de sugestóes consideradas aceitáveis (as quais podem dar origem a novos problemas). É um procedimento salutar para a construção de um processo de intervenção adequado à natureza do processo de aprendizagem vislumbrado.

Nessa direção, cumpre registrar que a preocupação de se considerar o contexto social e cultural no qual os sujeitos - educandos e educadores - estáo inseridos envolve, acima de tudo, o desejo de construção de uma proposta pedagógica - educacional, cultural, política, acadêmica - em que as hipóteses incompletas que os sujeitos formulam, seus saberes 'parciais', exercem papel preponderante quanto ao envolvimento pessoal. Parece ser esse um dos condicionantes da permanência efetiva, e com sucesso, do educando adulto no processo de escolarizaçáo, sobretudo, de ampliação das relaçóes com o mundo à sua volta, incluindo o mundo letrado.

Assim, cumpre considerar os projetos Peja/Unesp como uma rede de pesquisas empíricas para interpretações outras dos condicionantes histórico-culturais que podem se produzir modos outros, na ação pedagógica em EJA que, para muito além de uma questão técnica, é uma questão política.

Para além das dimensôes científica, tecnológica, de formação, o conhecimento se consolida como componente da cultura geral do cidadão que pode ser observada na linguagem corrente, no ambiente de trabalho, na imprensa, nas leis, na propaganda, nos jogos, nas brincadeiras e em muitas outras situaçóes do cotidiano, o que requer o constante 
exercício do raciocínio criativo, da imaginação, do cálculo mental, o que conduzirá a uma situação de aprendizagem e ensinagem escolar ou cotidiana duradoura, longeva, instigante, prazerosa. A considerar-se, ainda, que a temática da resolução de problemas envolve aportes linguísticos, psicológicos, conceituais, socioculturais dos indivíduos, que pode ocorrer em um ambiente de descobertas para aprender e ensinar, no qual não se hesite em experimentar, levantar hipóteses, reelaborá-las mesmo correndo o risco de cometer enganos.

\section{ALGUMAS CONSIDERAÇÕES: TRAVESSIAS PRODUZIDAS. OU POR ONDE SE RECOMEÇA...}

Com o intuito de trazer à discussão a educação de jovens e adultos como uma possibilidade de realizar-se nos espaços férteis da extensão universitária, exemplificando com o Peja/Unesp, que tem sido um lócus privilegiado de formação e estudos, nos últimos 14 anos, tivemos a intenção de dar certa visualidade ao campo de invenção que se descortina nesse fazer.

Consideramos a ideia de aprendizagem e ensinagem como constituintes de um processo que carrega preocupaçóes educacionais, culturais, políticas, mas também aportadas nas tecnologias (dispositivos da vida contemporânea), no fazer científico (levantamento de situaçóes-problema, reflexão e argumentação), no compartilhamento de objetos culturais (materializados nos objetos de leitura, escrita, cálculo), com vistas a uma formação que se quer humana nos múltiplos aspectos aí considerados. De um lado estão as exigências ao trabalhador pelas tecnologias de informação e as exigências de uso social do conhecimento que nos impóem pensar num processo de ensino em EJA no qual o sujeito possa reorganizar questóes, levantar hipóteses, experimentar encaminhamentos desenvolvendo um raciocínio argumentativo, de modo a estimular a construção de estratégias para resolução de problemas postos pela ação cotidiana, a discussão dos resultados e uma atitude permanente de busca de autonomia. De outro lado, pela especificidade na atuação, as reflexôes acerca da proposta de formação de educadores do Peja, fundamentada em uma metodologia que possibilita a investigação e a discussão 
das dificuldades e das necessidades dos educandos, articulando prática e teoria como movimento e interrelação, apontam para a possibilidade de ser este um caminho promissor para introduzir mudanças efetivas em suas práticas pedagógicas, mediadoras de aprendizagens e "ensinagens" significativas.

Ao eleger como fonte e objeto material de reflexão os registros individuais ou coletivos que são feitos oralmente ou por escrito, nos cadernos a esse fim destinados (também imagens), e materiais produzidos no dia a dia dos encontros, didáticos (jogos) ou de escolhas subjetivas (caderno de poesias), emergem temas que requerem estudos e discussóes, aos quais devemos estar atentos, uma vez que têm ressonância na identidade pessoal e social, no posicionamento do sujeito em contextos sociais diversos, na constituição subjetiva que impulsiona múltiplas esferas da vida.

Ao almejar como contribuição uma análise sistemática das fontes a que recorremos para produzir as propostas de intervenção e reflexão, nos deparamos com um lugar inusitado a nosso ver, que ocupam as práticas efetivamente culturais: as fontes se desvelam nas práticas, nos processos de interlocução em que a fala de cada um/uma - educador/a e educando/a - pesquisador/a concretiza motivos, desejos, envolvimento, num movimento constante do fazer, do aprender, do pensar e pensar-se no mundo. Assim também nos processos educacionais.

\footnotetext{
Eu atravesso as coisas - e no meio da travessia não vejo!

- só estava era entretido na idéia dos lugares de saida e de chegada.

Assaz o senhor sabe: a gente quer passar um rio a nado, e passa;

mas vai dar na outra banda é num ponto mais embaixo, bem diverso do que em primeiro se pensou (...) o real não está na saída nem na chegada: ele se dispóe para a gente é no meio da travessia...

(João Guimarães Rosa, 2005)
} 


\section{REFERÊNCIAS}

ARAÚJO, M. A. et al. (Elaboração) Guia de Extensão Universitária da UNESP 2012. 3. ed. São Paulo: UNESP, PROEX, 2012. Disponível em <http://www. Unesp.br/proex>. Acesso em: 10 de fevereiro de 2015.

ARROYO, M. G. Alfabetizaçáo de jovens e adultos em tempos de exclusão. Alfabetização e Cidadania. São Paulo, n 11, p. 9-20, 2001.

BAKHTIN, M. Marxismo e Filosofia da linguagem. São Paulo: Hucitec, 1986.

BRASIL, Ministério da Educação e do Desporto. Educação de Jovens e Adultos/ Proposta Curricular. $1^{\circ}$ segmento do ensino fundamental. Brasília: MEC/Ação Educativa, 1999.

- Educaçáo de Jovens e Adultos/Proposta Curricular. 20 segmento do ensino fundamental. Brasília: MEC, 2002.

CAMARGO, M. R. R. M. Palavras e imagens na Educação de Pessoas Jovens e Adultas: Onde está o sujeito? Cadernos de Linguagem e Sociedade. 2014. Disponível em: <http://seer.bce.unb.br/index.php/les/article/view/10460>. Acesso em: 15 de fevereiro de 2015.

CARVALHO, R. T. O discurso curricular intercultural na educação de jovens e adultos e a produção de subjetividades. Educação e Pesquisa, v. 38, n. 1, p. 47-61, São Paulo, jan./mar. 2012.

CERTEAU, M. de. A invenção do cotidiano: artes de fazer. Trad. Ephaim Ferreira Alves. 3. ed. Petrópolis: Vozes, 1998.

FREIRE, P. Pedagogia da Autonomia: saberes necessários à prática educativa. São Paulo: Paz e Terra, 1997.

FERRARO, A. R. História quantitativa da alfabetização no Brasil. In: RIBEIRO, V. M. (Org.). Letramento no Brasil. São Paulo: Global/Açáo Educativa, 2004, p. 195-207.

MARQUES, A. F.; ZANATA, E. M. Como estou me tornando um professor. In: CAMARGO, M. R. R. M.; FURLANETTI, M. P. F. R. (Orgs.). Educą̧ão de Pessoas Jovens e Adultas - Múltiplas Faces de um Projeto Educacional. São Paulo: Editora Unesp; Cultura Acadêmica, 2010, p. 95-121.

MIGUEL, J. C. Educação, linguagem e cultura: implicaçóes para o desenvolvimento de programas de ensino de Matemática para jovens e adultos. In: CAMARGO, M. R. R. M.; LEITE, C. D. P.; CHALUH, L. N. (Orgs.). 
Linguagens e Imagens: educação e políticas de subjetivação. 1. ed. Petrópolis: DP et Alii, 2014, p. 159-180.

PEDRALLI, R; CERUTTI-RIZZATTI, M. E. Evasão escolar na educação de jovens e adultos: problematizando o fenômeno com enfoque na cultura escrita. Rev. bras. linguist. apl., Belo Horizonte, v. 13, n. 3, 2013.

ROSA, G. Grande Sertão Veredas. Nova Fronteira, 2005.

SERRA, E. D’A. Políticas de promoção da leitura. In: RIBEIRO, V. M. (Org.). Letramento no Brasil. São Paulo: Global/Ação Educativa, 2004, p. 65-85.

SNYDERS, G. A alegria na escola. Rio de Janeiro: Zahar, 1994.

VIGOTSKI, L. S. A construção do pensamento e da linguagem. Trad. Paulo Bezerra. São Paulo: Martins Fontes, 2001.

\section{NOTAS}

1. As unidades localizam-se nas cidades de Araraquara, Assis, Bauru, Marília, Presidente Prudente, Rio Claro e São José do Rio Preto.

2. São diversas as formas de registro que fazem a memória material do Peja. Como exemplo, indicamos os relatórios anuais, os dados produzidos em projetos de pesquisa desenvolvidos, os cadernos de campo no cotidiano das atividades, a produçáo de educandos que arquivamos.

3. Adotamos a combinação de letras maiúsculas para referenciar os sujeitos no texto visando à preservação de identificação.

4. Entre as açôes do Peja/Unesp está a constante interlocução com professores em exercício da escola pública.

Recebido em 20 de fevereiro de 2015.

Aprovado em 29 de maio de 2015.

DOI: http://dx.doi.org/10.1590/CC0101-32622015723763 